\title{
Notes on the vocalizations of Grey Penduline-tit (Anthoscopus caroli)
}

Peter Boesman

In the following we briefly analyze and compare voice of the different races of Grey Penduline-tit (Anthoscopus caroli). We also try to quantify the extent of any vocal differences using the criteria proposed by Tobias et al. (2010), as a support for taxonomic review.

We have made use of sound recordings available on-line from Xeno Canto (XC) and additional recordings kindly forwarded by Michael Mills.

There are very few recordings available of this species.

Song of race sylviella is a high-pitched trill with a duration of $c 2-3 \mathrm{~s}$ :

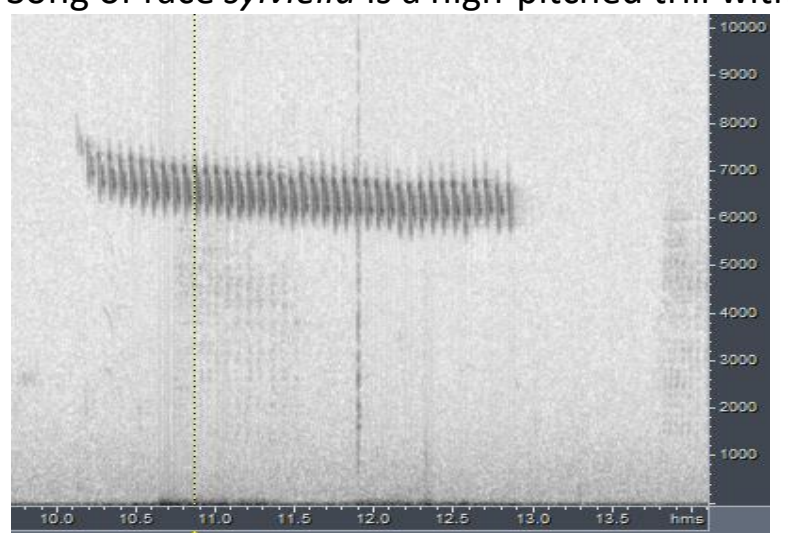

Other races (not all available) have a different song (a high-pitched note repeated several times, usually alternated with one or two very short notes)
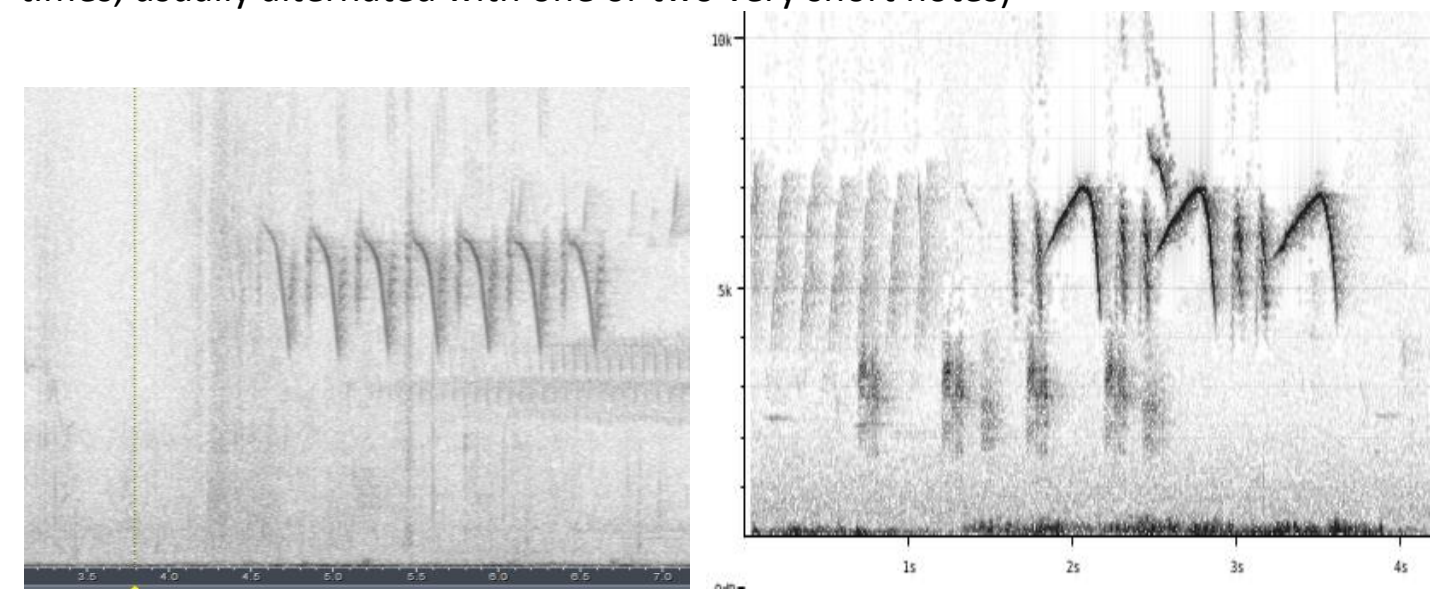

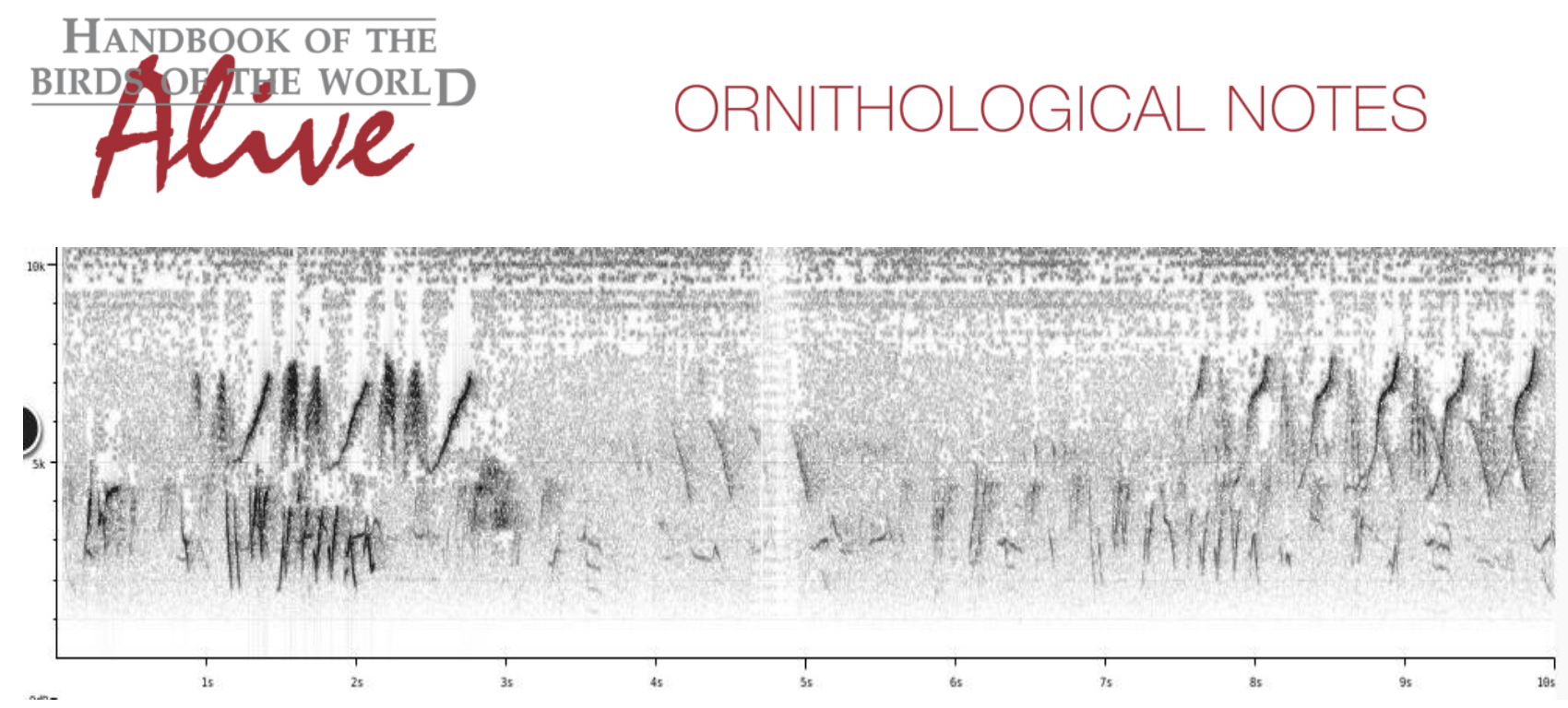

This is obviously a striking vocal difference, which could be quantified based on pace, \# of notes, note length etc. and would obviously reach a very high vocal score of about $3+4=7$ when applying Tobias criteria.

The exact geographical boundaries of this change in voice are however unclear. Zimmerman et al. (1996) describe the high-pitched trill for race sylviella. HBW Alive (Madge 2016) repeats this, but adds that pallescens is said to be a high-pitched trill which slowly fades.

In Borrow \& Demey (2014) description of song corresponds to the 'other races' but it is not clear if this is referring to race ansorgei. Given that ansorgei is also the race occurring in Angola, and the comment of Michael Mills (in litt.) that Angolan birds sing like 'other races' this seems likely.

Further study is clearly needed to get a better understanding of the geographical distribution of the two vocal groups.

As a final note, we can indicate that Mouse-coloured Penduline-tit $A$. musculus of Kenya and Ethiopia has also a trilled song, but with clearly different pitch and pace:

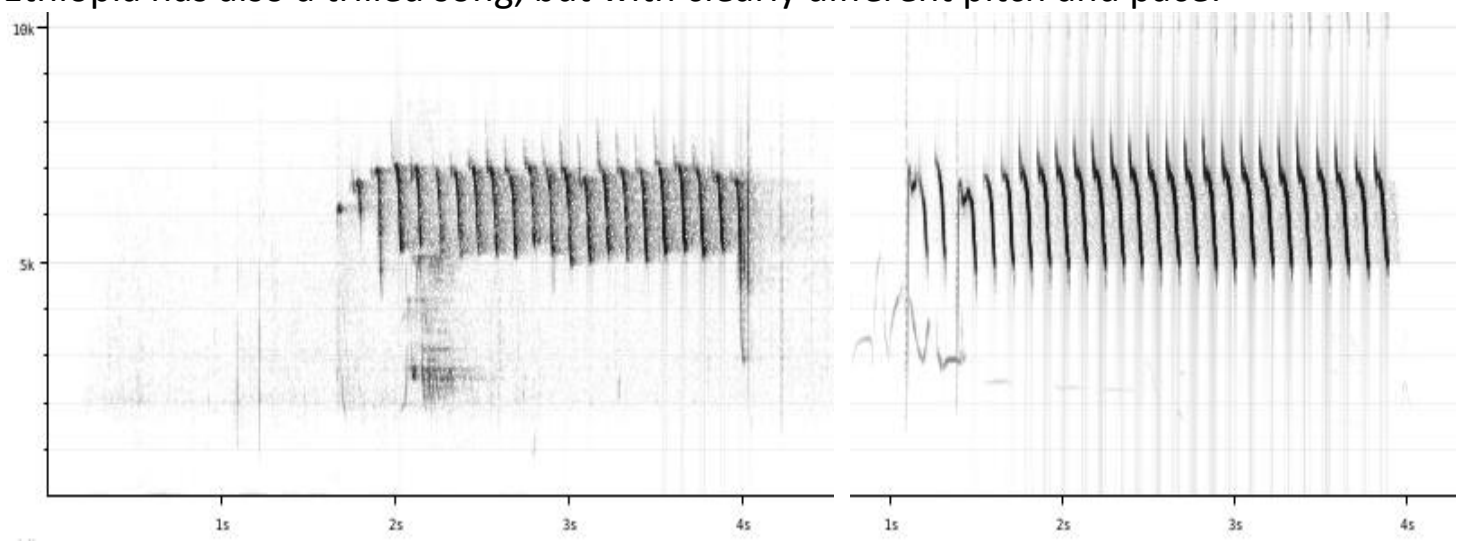

This note was finalized on 11th April 2016, using sound recordings available on-line at that moment. We would like to thank in particular the sound recordists who placed their song recordings for this species on XC: Charles Hesse, Jelmer Poelstra, and Michael Mills. 


\section{References}

Borrow, N. \& Demey, R. (2014) Birds of Western Africa. Second edition. Christopher Helm, London.

Madge, S. (2016). Grey Penduline-tit (Anthoscopus caroli). In: del Hoyo, J., Elliott, A., Sargatal, J., Christie, D.A. \& de Juana, E. (eds.). Handbook of the Birds of the World Alive. Lynx Edicions, Barcelona. (retrieved from http://www.hbw.com/node/59962 on 11 April 2016).

Tobias, J.A., Seddon, N., Spottiswoode, C.N., Pilgrim, J.D., Fishpool, L.D.C. \& Collar, N.J. (2010). Quantitative criteria for species delimitation. Ibis 152(4): 724-746.

Zimmerman, D.A., Turner, D.A., Pearson, D.J. (1996) Birds of Kenya and Northern Tanzania. Christopher Helm, London.

\section{Recommended citation}

Boesman, P. (2016). Notes on the vocalizations of Grey Penduline-tit (Anthoscopus caroli). HBW Alive Ornithological Note 419. In: Handbook of the Birds of the World Alive. Lynx Edicions, Barcelona. (retrieved from http://www.hbw.com/node/1253828 on 7 December 2016). 